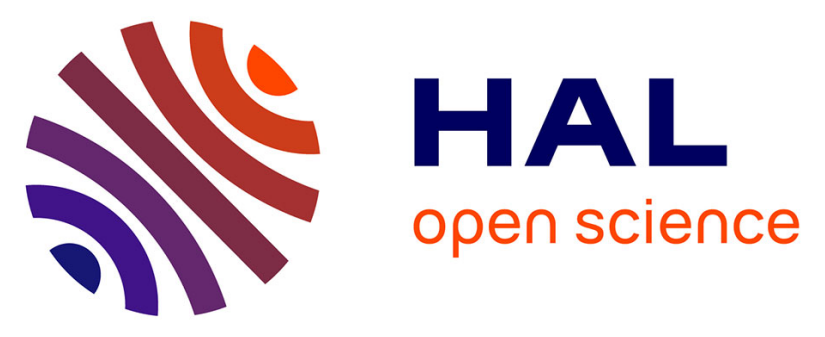

\title{
Supercooled Liquid Serum Physiologic Solution Instantly Crystallized on the Nurse Table Used for Cooling of Periorbital Region During Rhinoplasty
} Aret Çerçi Özkan, Erdem Güven, Berna Toktaş, Uygar Kizanlik, Onnik Agbulut

\section{- To cite this version:}

Aret Çerçi Özkan, Erdem Güven, Berna Toktaş, Uygar Kizanlik, Onnik Agbulut. Supercooled Liquid Serum Physiologic Solution Instantly Crystallized on the Nurse Table Used for Cooling of Periorbital Region During Rhinoplasty. Aesthetic Plastic Surgery, 2019, 43 (2), pp.453-456. 10.1007/s00266-0181287-7 . hal-02179731

\section{HAL Id: hal-02179731 \\ https://hal.sorbonne-universite.fr/hal-02179731}

Submitted on 11 Jul 2019

HAL is a multi-disciplinary open access archive for the deposit and dissemination of scientific research documents, whether they are published or not. The documents may come from teaching and research institutions in France or abroad, or from public or private research centers.
L'archive ouverte pluridisciplinaire HAL, est destinée au dépôt et à la diffusion de documents scientifiques de niveau recherche, publiés ou non, émanant des établissements d'enseignement et de recherche français ou étrangers, des laboratoires publics ou privés. 


\title{
Supercooled Liquid Serum Physiologic Solution Instantly Crystallized on the Nurse Table Used for Cooling of Periorbital Region During Rhinoplasty
}

\author{
Aret Çerçi Özkan' ${ }^{1}$ • Erdem Güven ${ }^{2} \cdot$ Berna Toktaş $^{3} \cdot$ Uygar Kızanlık $^{3}$ • \\ Onnik Agbulut $^{4}$
}

\begin{abstract}
Introduction Formation of less periorbital ecchymosis in post-operative period of rhinoplasty is a popular trend. We present the use of instantly crystallizing supercooled serum physiologic solution for periorbital cooling.

Physics of Supercooling There are circumstances in which water temperature drops below its freezing point, but no phase transition happens while water remains in the liquid phase. This is called supercooling. Pure water can be supercooled below the freezing temperature without transforming into ice. Tap water will not supercool because it contains impurities that serve as nucleation sites for crystallization. For freezer temperatures in the range of $-4{ }^{\circ} \mathrm{C},-6{ }^{\circ} \mathrm{C}$, and $-8{ }^{\circ} \mathrm{C}$, nucleation was not observed
\end{abstract}

Electronic supplementary material The online version of this article (https://doi.org/10.1007/s00266-018-1287-7) contains supplementary material, which is available to authorized users.

Aret Çerçi Özkan

aretmd@hotmail.com

Erdem Güven

erdem@drerdemguven.com

Onnik Agbulut

onnik.agbulut@sorbonne-universite.fr

1 Private Practice in İstanbul, İncirli Caddesi Bayrak Apt. No 89/7, 34147 Bakırköy, İstanbul, Turkey

2 Beşiktaş, İstanbul, Turkey

3 Scrub Nurse in a Private Hospital, Memorial Bahçelievler Hastanesi Bahçelievler Mahallesi, Eski Londra Asf Cd No: 227, 34180 Bahçelievler, İstanbul, Turkey

4 Institut de Biologie Paris-Seine (IBPS), CNRS, UMR 8256, Inserm ERL U1164, Biological Adaptation and Ageing, Sorbonne Université, 75005 Paris, France and pure water remained in the supercooled condition for a long time.

Description of the Technique Sterile serum physiologic solution at $+5{ }^{\circ} \mathrm{C}$ can be supercooled in the freezer at $-14{ }^{\circ} \mathrm{C}$ only between the 257 and 277 min time interval. But when it is supercooled in the freezer at $-8{ }^{\circ} \mathrm{C}$ it is possible to save it in liquid form for at least 7 days as we have observed in our trials.

Clinical Use and Discussion It is easily possible to transform this supercooled liquid sterile serum physiologic within a few seconds into moldable snow-like ice that can be used safely and more nicely rather than solid ice for periorbital cooling in rhinoplasty operations. Its sterile inner bag is held tight and struck over the sterile nurse table and it crystallizes within a few seconds. For frozen solutions, tearing of the inner plastic bag and extracting the ice and then crushing of big masses of ice to small pieces is exhaustive and a time-consuming process. The temperature of the supercooled fluid will be zero at the moment of nucleation with no risk of frostbite. The crystallized serum physiologic solution preserves its ice-gel form for nearly 25 min.

Conclusion The instant crystallization of supercooled liquid serum physiologic solution can be applied as a tissue cooling method in rhinoplasty and in several other surgical procedures.

Level of Evidence IV This journal requires that authors assign a level of evidence to each article. For a full description of these Evidence-Based Medicine ratings, please refer to the Table of Contents or the online Instructions to Authors www.springer.com/00266.

Keywords Supercooling $\cdot$ Rhinoplasty $\cdot$ Cooling $\cdot$ Ice 


\section{Introduction}

Formation of less and less periorbital ecchymosis in the immediate post-operative period of rhinoplasty is a recent popular trend. Patients prefer to have better and short recovery periods, so as not to face long interruption periods of their careers and social lives.

Infiltration of adrenaline solution, steroids, hypotensive anesthesia, meticulous right plane dissection, intra-operative and post-operative periorbital cooling, topical use of Arnica cream are all important conservative factors for reduction of periorbital ecchymosis in rhinoplasty. Nasal packing and periosteal elevation before osteotomy increase these postoperative morbidities [1]. Recently, ultrasonic devices and a full open approach are also claimed to be effective for reduction of periorbital ecchymoses [2].

In this paper, we will focus on intraoperative periorbital cooling by way of a very innovative method. Usually, rhinoplasty surgeons either use cold serum physiologic solution in liquid form or in solid ice form for periorbital cooling. In this study, we present the use of instantly crystallizing supercooled serum physiologic solution for periorbital cooling.

\section{Physics of Supercooling}

There are circumstances in which water temperature drops below its freezing point, but no phase transition happens while water remains in the liquid phase. This condition is called supercooling [3]. Pure water can be substantially supercooled below the freezing temperature without transforming into ice whereas mineral water or tap water will not supercool very well because they contain impurities that can lower the freezing point of the water or else serve as nucleation sites for crystallization. However, lacking any such nucleus, the liquid phase can be maintained all the way down to the temperature at which crystal homogeneous nucleation occurs. The achievement of supercooling can be enhanced by adding solutions or by applying hydrostatic pressure [4]. Nucleation caused by electrostatic attraction between water polar molecules is referred to as homogeneous nucleation. If nucleation happens with the aid of an extrinsic nucleator, it is referred to as heterogeneous nucleation [3]. Striking a supercooled serum physiologic bag over a counter, touching the supercooled fluid on a frozen surface or direct touching with an ice piece initiates heterogeneous nucleation.

Supercooled liquid occurs naturally in high altitude clouds. They contain the droplets of water that, in the absence of seed crystals and vibration, do not form ice despite the low temperatures. Supercooling was discovered already in 1724 by Fahrenheit, but even today the phenomenon remains a subject for intense discussions. Supercooled liquid possesses many physical properties that differ anomalously from warm liquid. As described in the literature, supercooled liquid contains a greater number of strong tetrahedral hydrogen-bonded molecules, structuring not easily compatible with forming crystalline hexagonal ice and these structures increase as the temperature is lowered [5]. A rigorous mechanical shock that produces enough energy to break this tetrahedral structure causing the transition of the water from the liquid to the solid state.

As described by Gholaminejad et al., in the standard condition for a freezer temperature range of $-4{ }^{\circ} \mathrm{C}$ $\left(24.8{ }^{\circ} \mathrm{F}\right),-6{ }^{\circ} \mathrm{C}\left(21.2{ }^{\circ} \mathrm{F}\right)$, and $-8{ }^{\circ} \mathrm{C}\left(17.6^{\circ} \mathrm{F}\right)$, nucleation was not observed and water remained in a supercooled condition for a long time. For freezer temperature of $-10{ }^{\circ} \mathrm{C}\left(14{ }^{\circ} \mathrm{F}\right)$ nucleation was random. For a freezer temperature of $-12{ }^{\circ} \mathrm{C}\left(10.4{ }^{\circ} \mathrm{F}\right)$ nucleation always happened and supercooling was rarely seen [3].

\section{Description of the Technique}

The above-mentioned results were obtained for distilled water. As sterile serum physiologic solution is used for periorbital cooling in rhinoplasties we tried to determine the optimum freezer temperatures and the time period that is convenient for the serum physiologic solution to be in a supercooled form. Sterile serum physiologic solution is also a very pure fluid and even if it is cooled in the freezer to subzero levels it still maintains its fluid consistency for some time interval without crystallization.

To find the supercooling condition of sterile serum physiologic solution, we performed two sets of experiments. The first trial has been done with a freezer having a $-14{ }^{\circ} \mathrm{C}$ $\left(6.8^{\circ} \mathrm{F}\right)$ temperature. Four plastic bags of $1000 \mathrm{cc}$. sterile serum physiologic solutions and one bag of $1000 \mathrm{cc}$ tap water were used to determine the precise time interval for the supercooling status of serum physiologic solution. Before beginning the trial, all serum physiologic solutions and the tap water were been kept at $5{ }^{\circ} \mathrm{C}\left(41{ }^{\circ} \mathrm{F}\right)$ in a refrigerator for 2 days. The first three $1000 \mathrm{cc}$. serum physiologic bags were inserted in the freezer with $30 \mathrm{~min}$ intervals. The fourth $1000 \mathrm{cc}$. wbag has inserted in the freezer with $20 \mathrm{~min}$ interval. The tap was inserted together with the first serum physiologic bag. All temperatures were measured with a digital thermometer with an external cabled sensor.

Our results demonstrated that when the freezer cover was opened for the first control at 210 min after insertion of the first serum physiologic bag, the tap water was found to be frozen but all serum physiologic bags were in liquid form. The freezer cover has opened for a second time 
283 min after insertion of the first serum physiologic bag. At this stage, the first serum physiologic bag was spontaneously crystallized but all other serum physiologic bags were in liquid form. At this moment, the second serum physiologic bag which was at $253 \mathrm{~min}$ of freezing was struck over the counter to initiate crystallization but no crystallization was observed showing it had not been supercooled yet. It is judged that the supercooling time interval should be somewhere between 253 and $283 \mathrm{~min}$ for serum physiologic solution. To narrow this time interval a little bit more, the freezer cover was opened for a third control at $277 \mathrm{~min}$ and for the fourth control at 257 min of freezing and they were immediately struck over the counter to initiate crystallization. Our results demonstrated that striking both resulted in crystallization which means both were in a supercooled condition at that moment (video 1). In this trial, the temperature of the ice-gel at the moment of the crystallization was $-1{ }^{\circ} \mathrm{C}$ which is also a very important finding.

The second trial was done with a freezer having a $-8{ }^{\circ} \mathrm{C}\left(17.6{ }^{\circ} \mathrm{F}\right)$ temperature. This was a simpler trial. Seven plastic bags of $1000 \mathrm{cc}$. sterile serum physiologic solutions were used. Due to the given information that nucleation was not observed at $-8{ }^{\circ} \mathrm{C}$ [3], a longer supercooled time interval was expected at this temperature so, quite different from the first trial, each bag of serum physiologic solution was picked up at 24-h intervals. Each morning each bag of serum physiologic was found to be supercooled and in liquid form without spontaneous crystallization and their crystallization was initiated by striking over the counter.

In summary, according to the above-mentioned 2 trials, sterile serum physiologic solution at $+5{ }^{\circ} \mathrm{C}$ can be supercooled in the freezer at $-14{ }^{\circ} \mathrm{C}$ between a 257 and 277 min time interval and can be forced to crystallize by striking on the counter. Before $253 \mathrm{~min}$ of freezing, the serum physiologic was not supercooled yet but after $283 \mathrm{~min}$ it spontaneously crystallized in the freezer. When serum physiologic solution is supercooled in the freezer at $-8{ }^{\circ} \mathrm{C}$ it is possible to save it in liquid form for quite a long time, at least 7 days, as we have observed in our trial. The huge difference between time intervals of the two trials in which serum physiologic solution is supercooled in liquid form is considerable.

\section{Clinical Use and Discussion}

If a circulating nurse or a staff carries this supercooled serum physiologic solution with care without shaking; he or she can bring it to the operating room still in liquid form. It is easily possible to transform this supercooled liquid sterile serum physiologic within a few seconds into moldable snow-like ice. This ice-gel can be used safely and more nicely than rocky solid ice for periorbital cooling in rhinoplasty operations. The supercooled sterile serum physiologic solution in liquid form can be requested when needed, for example, before lateral osteotomy. Its sterile inner bag is held tight and struck over the sterile nurse table and in a very magical instant within a few seconds, it is crystallized into an ice-gel, which is not rock-solid but moldable ice (video 2).

Transfer of instantly crystallized supercooled ice-gel in a sterile metal bowl is always easier than the transfer of the rock-solid ice. Removal of the inner plastic bag by tearing it and extracting the ice and then crushing of big masses of ice to small pieces by the scrub nurse is not very practical but exhaustive and a time-consuming process. The scrub nurse may injure herself during the preparation of ice cubes, or may harm the devices which are used for this preparation (video 3). However, striking the supercooled serum physiologic fluid and its instant crystallization takes just $3-5 \mathrm{~s}$ and after cutting the inner bag with scissors it easily slides in a metal bowl in $2 \mathrm{~s}$.

The temperature of the supercooled fluid will be zero at the moment of nucleation regardless of its previous temperature [3]. However, this has been relevant for pure water for that study. In our trial in which we used serum physiologic solution, the temperature at the time of crystallization was $-1{ }^{\circ} \mathrm{C}$. This temperature has been measured by inserting the sensor of the digital thermometer inside the ice-gel. This situation may be related to the amount of salt in the serum physiologic solution which is different than pure water. This temperature is very important because there will be no risk of frostbite with this type of tissue cooling with $-1{ }^{\circ} \mathrm{C}$. However, while using the solid ice cubes it's not easy to estimate the temperature and this may raise the risk of frostbite damage to tissues.

The ice-gel form of the instantly crystallized serum physiologic solution has the tendency to take the shape of the gauze that is laid over the nose and the periorbital region which provides more homogeneous cooling of tissues and it is more sticky and moldable to the gauze compared to the solid ice. Ice-gel also doesn't detach from the location it has settled in. Solid ice pieces have the tendency to fall down easily. In addition, the ice-gel form of the instantly crystallized serum physiologic solution is conserving the coolness around the periorbital region more effective and longer than cold liquid serum physiologic solution. The crystallized serum physiologic solution preserves its ice-gel form for nearly $25 \mathrm{~min}$.

In this study, we described two methods to obtain a supercooled serum physiologic solution. Freezer temperatures cooler than $-14{ }^{\circ} \mathrm{C}$ cannot be recommended to prepare supercooled liquid serum physiologic solution ready to use in rhinoplasty; for $30 \mathrm{~min}$ or $1 \mathrm{~h}$ time period 
that the serum physiologic solution is in supercooled form is not practical for use in a surgical procedure. However, the potential of saving the serum physiologic solution in supercooled form for a long time in a freezer with a temperature of $-8{ }^{\circ} \mathrm{C}$ ( 7 days in our second trial) provides the opportunity for its use in rhinoplasty operations for periorbital cooling.

The trial that we performed at $-14{ }^{\circ} \mathrm{C}$ really was not useful for practical use. Because of the $30 \mathrm{~min}$. supercooling is not clinically applicable. However, the trial that we performed at $-8{ }^{\circ} \mathrm{C}$ is highly applicable for clinical use because serum physiologic solution stays as a liquid for several days in $-8{ }^{\circ} \mathrm{C}$. So it is easily possible to obtain practical and highly reproducible crystallization at that specific temperature. Just before starting to do lateral osteotomy the supercooled solution can be instantly crystallized and easily used for periorbital cooling. The senior author uses this in all of his rhinoplasty operations. Evidence also exists for freezers with a temperature of $-6{ }^{\circ} \mathrm{C}$ that this temperature may result in a permanent condition of supercooling [3].

There is another way to obtain instant crystallization of the supercooled serum physiologic solution. If supercooled serum physiologic in liquid form is poured in a sterile metal bowl previously frozen in $-14{ }^{\circ} \mathrm{C}$, this serum again instantly crystallizes immediately by touching the frozen bowl by means of heterogeneous nucleation. But this is little troublesome because of the need for an extra freezing of the metal bowl. We show this phenomenon in video 4 (video 4). It's recommended to cover the sterile bowl with a plastic bag before freezing to prevent soaking of sterile packing. Preparing the instantly crystallized ice-gel by touching of the supercooled liquid to the sterile frozen bowl has one additional advantage. As the inner bag of the serum physiologic solution is not torn or cut and the serum is simply poured with this technique, the potential risk of contamination decreases considerably. Normally, the outer non-sterile layer is torn and opened by the circulating nurse or staff and the inner sterile layer is pulled out usually by a scrub nurse or rarely by the doctors can be seen at the beginning of video 3. During the process of pulling the inner layer apart, there may be some risk of contamination.
But if the circulating nurse holds the inner bag and scrub nurse cuts the port of the serum bag with sterile scissors, then if the circulating nurse pours the serum into the frozen sterile bowl there will be no risk of contamination.

\section{Conclusion}

The instant crystallization of supercooled liquid serum physiologic solution is an interesting phenomenon that can be applied as a periorbital cooling method in rhinoplasty operations with several advantages. It is a good alternative to other cooling techniques and can also be used in several other surgical procedures in other specialties such as orthopedics, cardiovascular surgery, neurosurgery etc. those requiring intra-operative cooling. The absence of frostbite risk is an especially remarkable feature of this phenomenon in cardiovascular surgery and neurosurgery.

\section{Compliance with ethical standards}

Conflict of interest All authors declare that they have no financial disclosures no conflict of interest.

\section{References}

1. Ong AA, Farhood Z, Kyle AR, Patel KG (2016) Interventions to decrease postoperative edema and ecchymosis after rhinoplasty: a systemic review of the literature. PlastReconstrSurg 137(5):1448-1462. https://doi.org/10.1097/prs.0000000000002101

2. Ilhan AE, Cengiz B, Caypinar EB (2016) Double-blind comparison of ultrasonic and conventional osteotomy in terms of early postoperative edema and ecchymosis. Aesthet Surg J 36(4):390-401. https://doi.org/10.1093/asj/sjv260

3. Gholaminejad A, Hosseini R (2013) A study of water supercooling. J Electron Cool Therm Control 3:1-6. https://doi.org/10.4236/ jectc. 2013.31001

4. Espinosa JR, Soria GD, Ramirez J, Valeriani C, Vega C, Sanz E (2017) Role of salt, pressure, and water activity on homogenous 1ce nucleation. J Phys Chem Lett 8(18):4486-4491. https://doi.org/ 10.1021/acs.jpclett.7b01551

5. Lehmkühler F, Forov Y, Büning T, Sahle CJ, Steinke I, Julius K, Buslaps T, Tolan M, Hakala M, Sternemann C (2016) Intramolecular structure and energetics in the supercooled water down to 255 K. Phys Chem Chem Phys 18:6925-6930 